\title{
LAS PIEZAS «MÁGICAS» DE RAMÓN DE LA CRUZ
}

\author{
Antonietta CALDERONE \\ Universidad de Messina
}

Espíritu ecléctico, abierto a la experimentación y siempre atento al gusto del público, Ramón de la Cruz terminaría por rendirse a la fascinación de la magia como recurso teatral de espectacularidad. Sin embargo, dotado de aquel sano equilibrio que a lo largo de su carrera le mantuvo lejos de todo exceso, o sea con la moderación del clasicista y el realismo del costumbrista (Caldera 1978), el Maestro se dejaría capturar por ella sólo en la medida en que su uso, además de permitirle la experimentación de nuevas fórmulas teatrales, le franqueara el aplauso del público también en un género que no era el que mejor se adaptaba a su personal temperamento artístico pero que sí era, en cambio, el más popular en la época en que vivió.

A estas conclusiones, de hecho, parecería llegarse tras haber echado una rápida mirada a su carrera artística, dedicando especial interés a los años durante los cuales compuso las piezas de las que aquí me voy a ocupar. Éstas están constituidas por dos comedias, Marta abandonada y carnaval de Paris (1762) y En vano contra el honor lidian encantos y amor (1773) y seis sainetes: La comedia de Valmojado (1773), Todo el año es carnaval (1773), El regimiento de la locura (1774), El entierro de la compañia (1776), El diablo autor aburrido (1779) y La soberbia castigada (1782). Qué colocación tienen estas piezas en el contexto teatral del momento constituye el propósito de este trabajo ${ }^{2}$.

${ }^{1}$ Para Ermanno, recordando las muchas conversaciones sobre «mágicos» y don Ramón.

${ }^{2}$ Por razones de espacio me ceñiré a las referencias bibliográficas imprescindibles para con el tema tratado, así como dedicaré mayor atención a las piezas menos conocidas. 


\section{Las comedias}

Marta abandonada y carnaval de París, comedia de gran espectáculo con la que se cerraba el año teatral 1761-1762, responde perfectamente a los requisitos de una pieza extensa de magia, además de formar parte de la bien definida serie de comedias que tienen a Marta la Romarantina y al genio infernal Garzón como protagonistas.

En su estudio introductivo a la primera edición impresa de la pieza, E. Caldera llamaba la atención sobre algunos aspectos de ésta. Ante todo, el presentarse como continuación de la famosísima Marta la Romarantina, compuesta por José de Cañizares y de la cual éste mismo había sacado una segunda parte, El asombro de Francia. Marta la Romarantina en 1740, con la probable intención por parte de Ramón de la Cruz de competir con Cañizares componiendo él otra segunda parte en la cual, aunque respetara el motivo central de la fábula, se apartaría «del modelo con el intento de obrar una reconstrucción más fiel de la historia y el ambiente»; de aquí que «el carácter urbano y costumbrista» y «un ideal de mayor contención y sobriedad» que privan en ella sustituyeran respectivamente «los motivos militares y aventureros» y al «lenguaje culterano y la escenografía aparatosa» del modelo. A la luz de estas reflexiones, se preguntaba Caldera si las opciones dramatúrgicas de Cruz no supondrían un «cambio en la historia de la comedia de magia, que habitualmente se iba desarrollando en ambientes fastuosos y era institucionalmente vinculada con lo excepcional e inverosímil», para terminar opinando que la de Ramón de la Cruz «tal vez fuera una feliz intuición que, de momento, no tuvo séquito por ser los tiempos todavía no maduros [...], aunque destinada a realizarse plenamente en la época romántica», pero que, de todas formas, era el resultado concreto de una nueva manera de interpretar el teatro en la que influía el gusto neoclásico (Caldera 1984, págs. 21-22).

En cuanto al distinto tratamiento de los lances mágicos, escasos y poco aparatosos respecto al modelo, estoy de acuerdo con el crítico en que en esta pieza la magia «es lo de menos», sobre todo si fijamos nuestra atención en el desarrollo de la acción central, donde destaca la finura con la cual Cruz traza el carácter de sus personajes, incluso de los secundarios, ahondando en la psicología de cada uno de ellos, lo cual no era usual en las comedias de gran espectáculo; en este contexto la magia, de hecho, no es funcional para el desarrollo de la acción, sino en «uno o a lo sumo dos» casos (Caldera 1984, pág. 34): la visión a distancia del Barón y M.me Morodán y la acción del Barón de apunalar el retrato de Marta. Sin embargo, por lo que atañe al tema que aquí estoy tratando, soy de la opinión que la comedia deba ser considerada como cabal comedia de magia en su aspecto espectacular, al hallarse en ella todos los consabidos actos mágicos que caracterizan el género: aparición-desaparición-transformación y vuelos-hundimientos de personas y cosas, a partir de la primera entrada espectacular de Garzón que sale 
de un nubarrón en llamas, pasando por la escena de la ya citada visión a distancia efectuada por el Demonio y la aparición, por mandato del mismo, de una «carroza etérea» que se lievará a Marta. A éstos hay que añadir otros episodios más cuya finalidad, en el plano de la ficción, es demostrar el poder de Garzón y, en el de la realidad -sobre todo los lances cómicos de los que los graciosos son protagonistas- el de divertir suscitando la maravilla o la carcajada: la aparición de un tocador de moda y dos mozos con sendos cofres de los cuales saldrán dos damas para engalanar a Marta, y la consiguiente desaparición del conjunto; la sustitución de Marta y la criada por dos brujas; la aparición de la cabeza del vejete de una escusabaraja; la transformación de tiestos de naranjos en soldados, etc.

Otro aspecto de la comedia que hay que resaltar -muy curioso, por cierto, a la luz de las consideraciones hechas hasta ahora- es el cambio de rumbo que sí, de alguna manera, Cruz imprime a la historia de la famosa maga, cuando en el desenlace supone que Marta se arrepiente gracias al Auxilio (bajo la forma de una figura velada y con un hacha), escenificando, por lo tanto, un concepto teológico que había tenido gran cabida en el teatro religioso de Calderón. Esta solución encaminada «a lo divino» afectaría a otra comedia de magia, Astucias del enemigo contra la naturaleza. Marta imaginaria, segundo asombro de Francia de José Concha, como expondré más adelante.

De muy distinto tema y tono es En vano contra el honor lidian encantos y amor, que fue compuesta como pieza «de gran espectáculo» para la Navidad de $1773^{3}$. El subtítulo La toma de Jerusalén remite a un aspecto de la pieza, el de tener dos desenlaces - hecho no insólito en muchas de aquella época--, que la haría susceptible de una doble lectura, según prevalezca el tema de un amor contrastado por el honor caballeresco o el tema del valor caballeresco junto al de un amor contrastado, aspecto curioso e interesante, pero irrelevante para el propósito de las observaciones que aquí expongo.

Según la perspectiva de una interpretación muy libre de algunos de los episodios de la Jerusalén conquistada de T. Tasso que tienen por protagonistas a Armida, Reinaldo, Tancredo y Erminia (Calderone 1983, págs. 154-157), desde la primera escena la comedia enfoca la atención del destinatario hacia dos temas igualmente centrales: la pasión amorosa entre el caballero cristiano Reinaldo y la maga mora Armida --que corre paralela a la pasión de Erminia por Tancredo-y la

3 De los tres ejemplares manuscritos que existen en la Biblioteca Histórica Municipal de Madrid, uno contiene datos sobre la fecha del estreno, el reparto de actores que la representó (la compañia de Eusebio Ribera) y las aprobaciones de la censura, en 22 y 23 de diciembre de 1773 , en las que resulta la autoría de Ramón de la Cruz. 
misión de Reinaldo que debe deshacer los encantamientos del bosque hechizado. El sitio de Jerusalén sirve sólo de fondo referencial a esta última empresa ${ }^{4}$.

Respecto a Marta abandonada, En vano contra el honor lidian encantos $y$ amor puede definirse una pieza «con magia», mejor que «de magia» según las características fundamentales del género: la protagonista no adquiere poderes mágicos como cualquier otra heroína, Marta por ejemplo, siendo ella maga desde su nacimiento; además, la demostración de estos poderes a través de actos mágicos espectaculares le interesa menos al autor que el desarrollo del conflicto entre dos sentimientos igualmente fuertes: el de la pasión amorosa entre Armida y Reinaldo y el del honor cristiano-caballeresco de Reinaldo que impide la realización de ese amor por ser Armida una maga mora; conflicto que, además, se desdobla e intensifica al crear el autor otra pareja marcada por un amor imposible (además de ser Erminia no cristiana, Tancredo sigue siendo fiel a la memoria de Clorinda) y otra pareja más en Reinaldo y Tancredo, basada en una estrecha relación fraternal en la que resaltan los más altos ideales del heroísmo, del espíritu de sacrificio, y, sobre todo, de una fe inquebrantable en Dios; ideales éstos que sobresalen mayormente en Reinaldo en cuanto condicionan su relación con Armida.

El conocimiento de las artes mágicas no le permite a Armida forzar la voluntad del caballero cruzado, el cual se rinde al amor sólo cuando la mujer amada renuncia a todos sus poderes y se convierte a la fe cristiana. Los lances mágicos que se escenifican en la comedia son, por lo tanto, poquísimos y todos ellos muy funcionales al desarrollo de la acción: el jardín que Armida ha encantado para hechizar a Reinaldo, y que es ilusión temporánea del más «real» espeso y espantoso bosque constituido por árboles y piedras en los que la maga ha transformado

${ }^{4}$ Con la conversión de Armida y la consagración del amor de los dos protagonistas principales, según mi opinión, termiraría la pieza ideada por Ramón de la Cruz, como parece confirmar la fórmula de cierre del ejemplar manuscrito presentado a la censura, verosímilmente por el mismo Cruz, en la que se hace sólo referencia a la continuación de las hazañas de Reinaldo: «Reinaldo: Vamos adonde nos llama / nuestra obligación, ufanos / de que el honor vencer supo / al amor y los encantos. / Todos: Pidiendo, antes, que el empeño logre perdón, si no aplauso.» Pero otra copia de las tres susodichas contiene una variante del parlamento de Reinaldo que expresa claramente su intención de trasladarse, con Tancredo, al campamento de los cruzados y tomar parte en la batalla final para la conquista de la ciudad santa, lo que, efectivamente, se escenifica a continuación. Tomada la ciudad, la comedia termina con una fórmula de cierre distinta que delata su filiación a la de una pieza heroico-caballeresca basada en las hazañas de Reinaldo y Tancredo. Sin embargo, el cambio no resulta violento y el largo añadido de nueve folios se podría considerar como continuación y remate de la historia, que, desde las primeras escenas, se presenta igualmente repartida entre el tema del amor contrastado y el del honor caballeresco. ¿Quiere esto significar que la comedia podía representarse con un epílogo heroico-militar - tan del agrado popular en aquel entonces- o con un desenlace apropiado para una comedia de amor, así como lo había concebido Ramón de la Cruz desde el principio? Y el autor de este largo añadido, ¿pudo haber sido el mismo Cruz? Al no ser mi intención la de aventurar hipótesis sin fundamentos que las sustenten, dejo la cuestión para otro momento. 
ya a muchos de los soldados cristianos, se transforma en dicho bosque, donde, saliendo de una densa nube, surge una sombra que canta una copla funérea y, más adelante, una fuente se transforma en un trono en el que aparece sentado el padre de Armida -el mago Hidraote- que hace mutis de la escena con un vuelo; un árbol se transforma en torre fuerte para aprisionar a Reinaldo, y la espada de Tancredo, de la que lo ha desarmado Armida, vuela en alto por todo el teatro. Tanto funcional y serio es el uso de la magia que no se verifica ningún episodio, incluso en los intermedios cómicos, en que se recurra a ella con el fin de divertir.

Resulta muy interesante entresacar de las acotaciones las -también éstas pocas, pero significativas- indicaciones sobre la utilería escénica para la realización de la escenografía y de los lances mágicos. En el jardín encantado de apertura, por ejemplo, habrá pájaros artificiales junto con «algunos naturales atados en los árboles, y que canten»; «un alambre oculto» realizará la acción mágica de Armida que desarma a Tancredo de su espada lanzándola al aire; el «velillo de plata» servirá para fingir los caños de una fuente; en la escena final (si se quiere tomar en consideración también el añadido), unos turcos «pintados que puedan mover el brazo del alfanje y cabeza» y otros «de paja» (que se desplomarán al suelo junto con el torreón de Jerusalén), estarán mezclados con las comparsas que hacen de turcos. Bien en el caso de los pájaros del jardín delicioso («para imitar más la naturaleza»), bien en el del torreón que se desmorona («todo lo más vistoso que sea posible y natural»), el autor conjuga la magnificencia de la escenografía -prerrogativa de la comedia de magia-con la sugerencia de que ésta realice una imitación de la realidad lo más perfecta posible. La misma atención se reserva a la música, el canto y el baile, especificando las indicaciones de ejecución ${ }^{5}$. En su versión primitiva, la comedia respeta las unidades de tiempo y de lugar. La de tiempo abarca algo más de veinte y cuatro horas; precisas indicaciones en los parlamentos sugieren que la acción de las jornadas I y II transcurre del alba de un día al alba del siguiente y que la de la jornada III empieza cuando han trascurrido tres horas desde el amanecer del segundo día, para terminar poco tiempo después. En cuanto a la de lugar, el examen de las acotaciones nos indica que la acción se desarrolla en un mismo espacio dividido en dos partes (el bosque encantado, donde también se encuentra el castillo de Armida, y la campiña donde moran los pastores), cuya proximidad está señalada por el río Jordán, que aparece en las dos mutaciones de la jornada I, y por el canto de los pastores que se oye («dentro») en la primera escena. El primer cambio de decorado de la jornada II representa

${ }^{5}$ En la jornada I: un coro pastoral alegre de trompas y flautas; una dulcísima sinfonía de todos los instrumentos con sordinas y flautas obligada con canto a voz sola y a dúo; un capricho y fermata de flauta; un preludio. En la jornada II: una cancioneta, un coro y orquesta brillante de clarines; una melancólica música de oboes, como que se quejan los troncos. En la III, en cambio, sólo toques de guerra. 
un «bosque corto» que no es sino una sección de la anterior «campaña pastoril»»; el segundo cambio se centra en el castillo, que ya se vislumbraba desde la misma campiña de los pastores, en una porción del bosque encantado; esta porción de bosque se ensancha en la tercera mutación, transformándose en un «bosque espeso» dominado por la presencia del ciprés encantado. En la jornada III, se vuelven a presentar ambientes ya escenificados: la «selva corta con algunas chozas y adorno» de los pastores y el bosque fatal, pero ya destruido y con las ruinas del castillo, entre las cuales destaca un elemento añadido, la fuente. Hay, por lo tanto, una evidente unidad de lugar que se relaciona a la de acción, lo que no se verifica, está claro, si se incluye en la fábula el añadido de la batalla y conquista de Jerusalén.

\section{Los sainetes}

¿Qué se entiende por «sainete de magia»? Si ya fue problemático, en los estudios pioneros sobre este tema (Caro Baroja 1974; Andioc 1976; Caldera 1983; Álvarez Barrientos 1989), definir la «comedia de magia» en el ámbito de las piezas extensas, aún sigue siéndolo para un género que, por su misma naturaleza y en la época de su mayor florecimiento, no sólo rehuye de lo fantástico y sobrenatural, sino que a menudo parodia su uso. Según M. Coulon, autora del valioso estudio sobre Le sainete à Madrid à l'époque de Don Ramón de la Cruz, los espectaculares efectos escénicos creados por las supuestas operaciones mágicas no sólo se habrían sustituido a las burlas tradicionales, provocando en el espectador más carcajadas que estupor, sino que, muy a menudo, habrían conseguido su propósito de desmistificar la magia, como demuestran muchos sainetes en los que ésta es fingida (El duende, El gracioso engaño del duende fingido, El duende fingido y valiente chasqueado, La fantasma) u objeto de burla. Por otro lado, dejando aparte su fuente de inspiración en la cotidianidad, el reducido número de sainetes de magia demostraría que la utilización de la tramoya podía resultar demasiado dispendiosa para un género que era de breve duración sea en las tablas sea en el repertorio de los cómicos. A tal propósito la estudiosa recuerda que la solución menos costosa hubiera sido la de aprovechar la tramoya usada en la pieza principal, como ocurrió con Todo el año es carnaval, sainete compuesto para ser representado entre la primera y la segunda jornada de Marta la Romarantina, en el carnaval de1773 (Coulon 1993, págs. 141-142); de hecho, tras el título, la primera acotación especifica: «El teatro estará en la escena que concluyó la primera jornada».

De los primeros resultados de una investigación mía in progress sobre el sainete de magia en la segunda mitad del siglo XVIII, parecería deducirse que ni la distinción entre entremés y sainete establecida por los autores, ni el tipo de 
idea escenificada, ni el uso de la tramoya son capaces de determinar las características esenciales del elemento mágico presente en este género menor, ni de aclarar tampoco las modalidades de su evolución. Ideas muy sencillas y recurso a la magia para pocas, y también éstas, sencillas acciones caracterizan los intermedios mágicos de la primera mitad del siglo XVIII, que siguen ateniéndose a las fórmulas del teatro clásico, con algún caso de verdadera innovación, como el de José de Cañizares (Calderone 2000). En los de la segunda mitad, en cambio, se nota una evolución del género hacia contenidos, estructuras y modalidades de ejecución más cuidadas e, incluso, refinadas. El aporte de Ramón de la Cruz es determinante en cuanto a las ideas; el modelo de la comedia de magia, en cambio, lo es en cuanto a la tipología de los recursos teatrales y de los actos mágicos: el uso de la tramoya, la invocación de los más famosos magos y magas (en lugar de los seres sobrenaturales), las consabidas acciones de vuelos, apariciones, desapariciones, transformaciones, etc., acompañadas por los mismos gestos rituales, como la patada, el silbido, pero todo desde una indiscutible perspectiva jocosa y paródica que lo diferencia de su modelo.

Por lo que se refiere a esta tipología de piezas breves en Ramón de la Cruz, es útil hacer una distinción entre aquellos sainetes en los que la magia es funcional al desarrollo de la acción-Todo el año es carnaval y La soberbia castigada y la clemencia premiada. El zapatero y la baronesa- y los que directamente parodian las comedias de magia -La comedia de Valmojado y El diablo autor aburrido- o sólo hacen referencia a éstas, o sea El regimiento de la locura y El entierro de la compañia.

Todo el año es carnaval pertenece a los sainetes teatrales que tratan el tema de la falta de un sainete para la función del día, problema endémico de las compañías en los años Setenta, que el autor soluciona de manera muy original y decididamente nueva ya que por primera vez, para salir del mal paso, se pide el auxilio del diablo (el conocidísimo y ya citado Garzón), en la persona del primer galán, Manuel Martínez; éste, mientra va dictando el texto del sainete al compañero Ruiz, gracias a sus poderes mágico-diabólicos hace que aparezca en el escenario lo que él va dictando: cinco distintas situaciones, propias de un sainete costumbrista urbano, basadas en el mutuo engaño de sus protagonistas.

Todo el año es carnaval es, por lo tanto, lo que se puede considerar un verdadero sainete de magia, como apunté hace algunos años, al editar el texto aún manuscrito (Calderone 1996), acompañándolo de una breve introducción crítica de la cual recuerdo aquí los puntos más pertinentes al tema del que me estoy ocupando. Ante todo, la novedad de recurrir a la magia que abarca mucho más que el simple propósito paródico y el aprovechamiento de la tramoya preparada para la comedia; la magia tiene aquí una finalidad dramático-funcional: 
Al desarrollarse la acción simultáneamente a la exposición del poeta «mágico» (vv. 261-262 y 352-354), en la escena se realiza la concretización del fenómeno teatral: el texto se materializa, la palabra se traduce ipso facto en accion, palabra y acto conviven.

A continuación, es interesante la definición que el autor da de la comedia de magia como género capaz de «divertir a todo trapo / al pueblo y especialmente / las viejas y los muchachos» (vv.72-74), muy parecida a la que años después daría Leandro Fernández de Moratín del teatro de Salvo y Vela (1944, pág. 311), opinión compartida por todos los escritores neoclásicos, desde Tomás de Iriarte (1805, pág. 42) hasta los redactores de la prensa periódica que ponían el grito en el cielo ante el peligro de deseducación que conllevaba la visión de tales «comediones» en el público que solía asistir a los teatros en los períodos de fiesta, es decir, criadas, sirvientes y niños. Finalmente, la consciencia de la novedad en escribir un sainete de magia, o bien, con palabras de Espejo: «con novedad ofrecer / sainetes del mismo palo / que la comedia» (vv.31-33), es decir sainetes en cuya ejecución interviniera la tramoya. Al uso de ésta se refiere Martínez cuando declara que con sus artes mágicas compondrá «un sainete extraño», como el reciente de Valmojado, que él define «fiesta», el cual gustó muchísimo al público (vv.184-188) por la tramoya utilizada. En él, uno de los payos metidos a actores, Baltasar, que tiene el papel de «diosa del cielo» en una comedia casera «de gran espectáculo», debe salir a la escena bajando desde lo alto en un balancín: «Empieza a bajar con cuatro cordeles un taburete y en él Baltasar [...]»; pero, a causa del inadecuado uso de la máquina de parte de los payos tramoyistas, el pobre Baltasar «se trastorna y queda agarrado boca abajo», y termina rompiéndose un hueso. Nada nuevo, como comenta a continuación Eusebio, el autor de la compañía capitalina, puesto que también a ellos, los profesionales, les suceden en Madrid «mil chascos de esos». Contra estos «chascos», como es sabido, arremetieron los críticos neoclásicos, poniendo en guardia sobre la mala ejecución técnica de los lances mágicos que comportaba no sólo la ruptura de la ilusión dramática, sino también «el peligro al que los cómicos están expuestos de romperse las piernas o las cabezas en sus vuelos, tramoyas y otras violentas mutaciones» (Memorial literario, enero de 1785, pág. 6). John Dowling refiere que Antonio Benito Cariga y el juz protector de teatros José Antonio Armona, al firmar la aprobación de El diablo autor aburrido mostraron preocupación «por este dragón que además debía arrojar llamas por la boca» (Dowling 1981, pág. 45).

Muy graciosamente, en su escenificación del episodio, Ramón de la Cruz retrata lo que quizás se verificara a menudo en los coliseos de Madrid, o sea que se recomendaba a los tramoyistas tener cuidado al ejecutar las maniobras, manteniendo bien tensas las cuerdas, y a los actores que no tuvieran miedo porque, en 
caso de que se cayeran, algún compañero evitaría que dieran directamente al suelo y que, por lo tanto, aun en peligro de caerse, siguieran representando.

Muy diferente, en cambio, en cuanto a tema, técnica y vis comica es La soberbia castigada y la clemencia premiada. El zapatero y la baronesa ${ }^{6}$, curioso sainete cuya acción se centra en dos parejas: la del zapatero Cosme y su mujer Úrsula, victima del carácter tiránico del marido, y la del Barón y la Baronesa, también ésta de carácter insufrible para con todos. En una noche de tormenta, unos peregrinos piden hospitalidad a ambas parejas pero no la obtienen porque, por un lado, la Baronesa los aleja con violenta hostilidad, y, por el otro, Úrsula teme la reacción violenta del marido; de repente, al comentar ella que éste se llevaría muy bien con la Baronesa, así como lo harían ella y el Barón, ya «que yo nací para duca / y ella para zapatero», sale por el escotillón un «mágico» que le asegura cambiarla de estado gracias al poder «de la ciencia de la magia» y le comunica que «al instante / invisible vendrá ella [la baronesa] / a tu alcoba, y tú a su casa / con hacer sólo esta seña» (Durán 1843, 335 a). A continuación, unos matachines sacan a Cosme de la cama y lo colocan, aún dormido, en el suelo de su alcoba, donde se encuentra ya la Baronesa, con el vestido de Úrsula. Las siguientes escenas son retratos paralelísticos de las reacciones en cada casa y entre las nuevas parejas: la Baronesa se niega a servir el café al zapatero sosteniendo que ella es la Baronesa, por lo cual el hombre termina por darle golpes con el tirapié y la obliga a besarle la mano; en casa del Barón, Úrsula se precia con su nueva ropa, pero rehusa tomar el chocolate, que no conoce y le disgusta, y es amable con todos y cariñosa con el Barón, quien no cree lo que está viendo y termina arrodillándose a los pies de su esposa y pidiéndole besar su mano. En este momento irrumpe en la sala la verdadera Baronesa, furiosa, violenta y para todos la mujer del zapatero. Llega, también, tras ella el zapatero armado de un bastón. Ambas mujeres, aterrorizadas, le piden protección al Barón. Al final sale el mago que aclara el enigma, resultado de la acción de su «ciencia» y vuelve a juntar las parejas originales. La Baronesa promete mudar de genio admitiendo que «el tirapié de este hombre / ha hecho este milagro»y Cosme el zapatero cierra la pieza con el consejo a los maridos: «Pues al tirapié, maridos, / con las que hay de genio malo, / porque éstas y las olivas / sólo dan el fruto a palos» (Durán 1843, 341 a).

Pieza curiosa, como la he calificado antes, es este sainete que se sale de los parámetros propios del género. Indudablemente es un sainete de magia, dada la presencia e intervención de un mago; sin embargo, la magia se reduce a ese úni-

"Este sainete presenta algún problema de atribución y de estreno. En Fernández Gómez (1993, pág. 600) es de probable autoria de Cruz y representado en junio de 1781; en Andioc-Coulon (1996, pág. 850) también de probable autoría de Cruz, pero representado el 3 de junio de 1782; Coulon (1993, pág. 172) hace referencia a él como pieza segura de nuestro sainetista. Aquí me sirvo de la edición impresa conocida como Colección DURÁN. 
co lance en el que se transforma a las dos mujeres e intervienen los matachines infernales, para el que no era necesario el uso de la tramoya, puesto que se podía resolver con un simple trueque de vestidos y la entrada y salida por un escotillón; incluso la orden del mago es anunciada por él «con hacer sólo esta seña», una seña sin especificar, que podemos suponer la más sencilla posible, la de la mano, por ejemplo. Pero lo que más llama la atención -y resultaría aún más chocante en su tiempo- es ese recurso al tirapié con propósito didáctico. Estoy perfectamente de acuerdo con M. Coulon-que lo interpreta como la pervivencia de una variante del antiguo «matapecados»-- que el fracaso de la pieza (nunca volvió a representarse) fue debido a esta solución rústica de corregir defectos delante de un público que el autor había acostumbrado a soluciones más refinadas (Coulon 1993, pág. 172). Falta de aparatosidad en una pieza que parecía prometerla, junto con una idea débil y una solución pasada de moda harian de este tardío sainete de don Ramón uno de los menos conocidos.

Un año después de Todo el año es carnaval don Ramón estrenó El regimiento de la locura, como entreacto de otra comedia de magia, También la magia se hereda, sexta parte del ciclo de El mágico de Salerno. Pedro Vayalarde. Esta vez, nuestro autor no compuso otro sainete «del mismo palo», sino que aprovechó la ocasión que le ofrecía la representación de una comedia de magia para tratar de este género teatral como ejemplo de aquel teatro «desarreglado» que la política gubernamental pretendía desterrar de los coliseos y en el que los detractores del sainetista incluian sus piezas breves y las zarzuelas; la magia, por consiguiente, servía tan sólo de pretexto para oponer el teatro de gusto popular (representado por el cantero Tomas Colorado, aficionado a las comedias de magia) al de corte neoclásico (representado por el «erudito de profesión», para el cual este tipo de teatro es «peste y necedad».

También en El entierro de compañía, estrenado por la compañia de Eusebio Ribera el 25 de mayo de 1776 , se lleva a las tablas otro problema que afectó a las compañías, especialmente en los años siguientes a 1774: la escasa concurrencia del público por la falta de piezas que fueran de su agrado. Para que la compañía de Eusebio Ribera, que está a punto de fallecer, pueda recobrar sus fuerzas, el supernumerario José Ibarro, que «a maquinista con Garzón se las apuesta», empieza a aplicarle una terapia de shock basada en «tramoyas» y «asaltos» y después el segundo barba Ponce le pone en las sienes unas «novedades», o sea comedias nuevas, sainetes nuevos, tonadas nuevas. Tramoya y novedades de todo tipo son, por lo tanto, los únicos remedios para que las compañías puedan sobrevivir económicamente.

Del mismo tono, pero con una declarada intención cómico-paródica, se representaba en 1779 El diablo autor aburrido, un perfecto sainete de magia en el que se finge que el Diablo - preocupado porque los actores de la compañía de 
Ribera, desalentados por la falta de asistencia de público al teatro puesto que no se representan piezas de su gusto, han decidido dedicarse a otro trabajo o a una vida retirada «en gracia de Dios»- decide tomar la apariencia del gracioso Chinitas y la autoria de la compañía para «mejorar sus esperanzas y mudar sus vocaciones» y así reconquistar sus almas perdidas. Pero acabará por renunciar a su propósito: de nada sirven las artimañas infernales, con actores convencidos de que la pieza que están ensayando no gustará, ya que, aunque no es mala, es «sin graciosos, / sin asaltos y sin magia». Es muy claro el mensaje lanzado por Ramón de la Cruz en los versos finales 7 , como bien apunta M. Coulon (1993, pág. 254): la decadencia de las compañías no depende ni del autor ni de los actores sino precisamente de aquellos que acusan de ignorancia al público aficionado a las comedias «de teatro».

Este sainete ofrece, además, otro interesante aspecto que indica su colocación e impacto en el contexto teatral del momento, como apunté hace años y paso a recordar textualmente:

Este diablo [Chinitas «vestido con alusiones de Diablo»], que baja al tablado («una selva oscura») en un «dragón de siete cabezas con ojos encarnados y un farol amarillo y encarnado en la cola», entre truenos y relámpagos; que pido ayuda a sus cuatro asistentes, «vestidos de diablos ridículos» también ellos, quienes, a su turno, salen o se hunden por los escotillones o vuelan, y a los cuales él muestra a distancia lo que está pasando en la sala del ensayo; este diablo -repito- parecería comportarse ni más ni menos como cualquier otro mágico demoníaco anterior si no recordara tan fuertemente - claro cstá, en versión entremesil- al específico protagonista de una desafortunada comedia de magia de José Concha, Astucias del enemigo contra la naturaleza. Marta imaginaria, segundo asombro de Francia, que había pretendido presentarse como una de las continuaciones (segunda) de Marta la Romarantina. Los recursos espectaculares y la estructura de la primera parte del sainete repiten, en efecto, los mismos expedientes de la comedia de Concha, quien había organizado su intriga siguiendo al pie de la letra los postulados tanto estructurales como teológicos de muchos autos sacramentales de Calderón, sobre todo en lo que concierne a la dramatización del demonio. La comedia, que quizás nunca fue estrenada (aunque sí repetidamente anunciada por los años 1775 y 1776), justamente por basarse en los recién prohibidos temas sagrados, fue refundida por J. López de Sedano, quien, tras expurgarla de todo lo malsonante en cuanto a religión y estilo y cambiarle el título en Marta aparente, obtuvo que se representara en la Navidad de 1779 . Recuerdo que El diablo autor aburrido

${ }^{7}$ Pues si hay demonios que cantan / y bailan en Bayalardes, / Rabicortonas y Martas, / que son argumentos serios, ¿qué mucho será que haya / demonios en entremeses? / Y por que aquellos que sacan / consecuencia del atraso / de los teatros de España / por esta especie, la vean / también ridiculizada, / y que no todo lo que es / diversión es ignorancia. 
se remonta a principios de aquel mismo año. Recuerdo asimismo que no fue Concha el primer autor en romper con el tradicional tratamiento fantástico de la historia de la famosa maga, deslizándose hacia la representación sagrada; había sido justamente Ramón de la Cruz el responsable del cambio de rumbo, cuando en 1762 escribía su primera comedia de magia, Marta abandonada y carnaval de París, como continuación de la primera comedia de Cañizares (Calderone 1996, pág. 133).

De lo dicho anteriormente se puede deducir que pocas veces, en su larga y prolífica actividad teatral, Ramón de la Cruz se sirvió de la magia en la composición de sus piezas; sin embargo, cuando lo hizo, dejó en ellas su huella personal o influyó en el género. Por un lado, en las comedias, se ciñó a una cierta «propiedad» de tema y escritura, reinterpretando la historia de Marta la Romarantina según una óptica costumbrista y burguesa y realizando en En vano contra el honor lidian encantos y amor un texto perfectamente «regular» según los controvertidos dictámenes neoclásicos. Por el otro, en los sainetes, dio demostración de su afán de experimentación de nuevas ideas y nuevas soluciones escénicas que pudieran agradar al público del patio, teniendo muy clara consciencia del tipo de operación teatral que estaba llevando a cabo: divertir a ese público suyo tan afícionado a la aparatosidad escénica (la magia servía para divertir) - y, de paso, informarle sobre los ataques que recibía por parte de los detractores de su teatro «popular»-y contraatacar a esos mismos detractores, recordándoles que «no todo lo que es diversión es ignorancia». 


\section{BIBLIOGRAFÍA}

Álvarez BARrientos, Joaquín, 1989. «Problemas de género en la comedia de magia», en Javier Huerta Calvo, Harm del Boer y Fermín Sierra MARTinez (eds.), Diálogos hispánicos de Amsterdam, 8/II, Amsterdam, Rodopi, II, págs. 301-310.

ANDIOC, René, 1976. Teatro y sociedad en el Madrid del siglo XVIII, Madrid, Fundación J. March/Castalia.

ANDroc, René y Mireille Coulon, 1996. Cartelera teatral madrileña del siglo XVIII (1708-1808), 2 vols., Toulouse-Le Mirail, Presses Universitaires du Mirail.

CALDERA, Ermanno, 1978. «Il riformismo illuminato nei «sainetes» di Ramón de la Cruz», en Letterature, I, Genova, págs. 31-50.

- 1983. «Sulla «spettacolarità» delle commedie di magia», en Ermanno CAldera (ed.), Teatro di magia, I, Roma, Bulzoni, págs. 11-32.

- 1984. «Introducción» a Ramón de la Cruz, Marta abandonada y carnaval de Paris, Felisa Martín Larrauri (ed.), Roma, Bulzoni.

CALDERONE, Antonietta, 1983. «Amore, scienza e trasgressione nella maga settecentesca», en Ermanno CALDERA (ed.), Teatro di magia, I, Roma, Bulzoni, págs. 147-164.

- 1996. «Todo el año es carnaval, sainete inédito de Ramón de la Cruz», en Joaquín Álvarez BARRIENTOS y José CHECA BELTRÁN (eds.), El siglo que llaman ilustrado. Homenaje a Francisco Aguilar Piñal, Madrid, C.S.I.C., págs. 131-152.

- 2000. «Tradizione e innovazione negli«entremeses» con magia di José de Cañizares», en Giovanni Battista DE CESARE (ed.), Drammaturgia e spettacolarità nel teatro iberico dei Secoli d'Oro, Salerno, Edizioni del Paguro, págs. 287-309.

Caro Baroja, Julio, 1974. Teatro popular y magia, Madrid, Revista de Occidente

Coulon, Mireille, 1993. Le sainete à Madrid à l'époque de Don Ramón de la Cruz, Pau, Publications de l'Université de Pau.

Cruz, Ramón de la, [1762, ms. 1-47-5 de la Biblioteca Histórica Municipal de Madrid], 1984. Marta abandonada y carnaval de París, Felisa MarTín LARRAURI (ed.), Roma, Bulzoni.

- 1928. La comedia de Valmojado, [ms. 1/162/37 de la Biblioteca Histórica Municipal de Madrid], Sainetes de don Ramón de la Cruz, en su mayoría inéditos. Colección ordenada por D. Emilio COTARELO Y MORI, Madrid, Bailly-Baillière, vol. II (NBAE n²6), págs. 190-196.

- [1773, ms. 1/170/25 de la Biblioteca Histórica Municipal de Madrid], 1996. Todo el año es carnaval, Antonietta CALDERONE (ed.), en Joaquín ÁlvAREZ 
Barrientos y José CHeCA Beltrán (eds.), El siglo que llaman ilustrado. Homenaje a Francisco Aguilar Piñal, Madrid, C.S.I.C., págs. 131-152.

- 1773. En vano contra el honor lidian encantos y amor, $\mathrm{ms} .1 / 112 / 1$ de la Biblioteca Histórica Municipal de Madrid.

- [1774], 1928. El regimiento de la locura, Sainetes de don Ramón de la Cruz, en su mayoria inéditos. Colección ordenada por D. Emilio COTARELO Y MORI, Madrid, Bailly-Baillière, vol. II (NBAE n²6), págs. 451-456.

- [1776, ms. 14521/26 de la Biblioteca Nacional de Madrid], 1791. El entierro de la compañia, Teatro o Colección de los Saynetes y demás obras dramáticas de D. Ramón de la Cruz y Cano, entre los Arcades Larisio, Madrid, Imprenta Real, vol. X, págs. 157-186.

- [1779, ms. 14602/15 de la Biblioteca Nacional de Madrid], 1981. El diablo autor aburrido, Sainetes, I, John Dowling (ed.), Madrid, Castalia.

- 1843. La soberbia castigada y la clemencia premiada, [ms. 14597/27 de la Biblioteca Nacional de Madrid], Colección de los sainetes tanto impresos como inéditos, de D. Ramón de la Cruz, con un discurso preliminar de D. Agustín DURÁN, y los juicios críticos de los Señores Martínez de la Rosa, Signorelli, Moratin y Hartzenbusch, Madrid, Imprenta de Yenes, vol. II, págs. 333-341.

Dowling, John, 1981. «Introducción» a Ramón de la Cruz, Sainetes, I, Madrid, Castalia.

Fernández Gomez, Juan Fernando, 1993. Catálogo de entremeses y sainetes delsiglo XVIII, Oviedo, Instituto Feijoo de estudios del siglo XVIII.

FERNÁNDEZ De MORATín, Leandro,1944. «Discurso preliminar» a Comedias, en Obras de Don Nicolás y Don Leandro Fernández de Moratín, B.A.E., II, Madrid, Atlas.

IRIARTE, Tomás de, 1805. Los literatos en cuaresma, en Colección de obras en verso y en prosa de D. Tomás de Yriarte, t. VII, Madrid, Imprenta Real, págs. 9-96. 